\title{
Biosimilars and Regulatory Authorities
}

\author{
Paola Minghetti $^{\mathrm{a}}$ Paolo Rocco $^{\mathrm{a}}$ Lucia Del Vecchio ${ }^{\mathrm{b}}$ Francesco Locatelli ${ }^{\mathrm{b}}$ \\ a Department of Pharmaceutical Sciences 'P. Pratesi', Università degli Studi di Milano, Milan, and bepartment of \\ Nephrology, Dialysis and Renal Transplant, A. Manzoni Hospital, Lecco, Italy
}

\section{Key Words}

Biosimilars - Epoetin alpha - European Medicines Agency (EMEA) guidelines $\cdot$ Regulatory authorities $\cdot$ Recombinant human erythropoietin

\begin{abstract}
The patent expirations for many biotechnological medicines have prompted the development of copies of biological medicinal products. Unlike generics, biosimilars are similar but not identical to their reference product, because their chemical characteristics are directly related to the manufacturing process which cannot be precisely duplicated. The regulatory policy for biosimilars is complex and in Europe it is regulated mainly by guidelines issued by the European Medicines Agency (EMEA); additional product-class specific guidelines have been developed as in the case of recombinant human erythropoietin (rHuEPO). In 2008, the experience gained with this drug has prompted the development of a new guideline, currently in draft. In this review we critically discuss aspects related to EMEA guidelines, particularly focusing on rHuEPO.

Copyright $\odot 2010$ S. Karger AG, Basel
\end{abstract}

\section{Introduction}

The patent expirations for many biotechnological medicines, such as epoetin alpha, filgrastim and somatropin, have prompted the development of copies of bio- logical medicinal products. At present, epoetin is the only biosimilar of interest in the field of nephrology. No other drugs related to chronic kidney disease (CKD) are in the pipeline. The effects and implications of the European Medicines Agency (EMEA) guidelines, together with clinical aspects of biosimilar epoetin alpha, will be discussed in this review.

\section{The Definition of Biosimilar}

In the European Community (EC), a copy which is claimed to be 'similar' to a reference medicinal product which has been granted a marketing authorization (MA) within the EC is defined 'similar biological medicinal product' or 'biosimilar'.

Unlike generics, biosimilars are similar but not identical to their reference products, because their chemical characteristics are directly related to the manufacturing process, which cannot be precisely duplicated. Thus, biosimilars require an approach to grant the MA, different from both originators and generics.

The regulatory policy for biosimilars is complex and in Europe it is mainly governed by guidelines issued by the EMEA. Besides general guidelines addressing quality, non-clinical and clinical issues, additional productclass specific guidelines have been developed and continually revised, as in the case of the guidance on products containing recombinant human erythropoietin (rHuEPO).

\section{KARGER \\ Fax +4161306 1234 \\ E-Mail karger@karger.ch}

www.karger.com
(C) 2010 S. Karger AG, Basel

$1660-2110 / 11 / 1171-0001 \$ 38.00 / 0$

Accessible online at:

www.karger.com/nec
Prof. Paola Minghetti

Department of Pharmaceutical Sciences 'P. Pratesi', Università degli Studi di Milano

via G. Colombo, 71, IT-20133 Milan (Italy)

Tel. +3902503 24639, Fax +390250324657

E-Mail paola.minghetti@unimi.it 


\section{MA Application for Biosimilars}

In the EC, technologically advanced medicinal products such as products developed by means of a biotechnological process (e.g. recombinant DNA technology) can be placed on the market only after a MA has been issued by the EC in accordance with the provisions of Regulation (EC) No. 726/04 [1] (centralized procedure). The centralized EC authorization was introduced in 1993, in order to maintain the high level of scientific evaluation and to preserve the confidence of patients and the medical professions in the evaluation process.

The application must be accompanied by a dossier containing the required data, presented in accordance with a standardized format, namely the Common Technical Document. The CTD is composed of five modules: Module 1 provides specific administrative data, Module 2 provides quality, non-clinical and clinical summaries, Module 3 provides chemical, pharmaceutical and biological information (quality), Module 4 provides non-clinical reports (safety), and Module 5 provides clinical study reports (efficacy) [2].

When patent rights, supplementary protection certificates and a relevant period of data protection (a 10- or 11-year period) expire, it seems unethical and uneconomical to ask other applicants to provide a full dossier for a copy of that particular medicinal product. Hence in the case of a copy of a small-molecule chemical entity (gener$i c s$ ), the applicant is not required to provide the results of preclinical tests and clinical trials if it is possible to demonstratethat the copycontainsthe sameactive substance(s) as that of a reference medicinal product authorized in the EC over a period longer than 8 years, and a bioequivalence demonstrated through appropriate bioavailability studies.

In the case of the copy of a biological medicinal product, the active substances are similar but not identical to the ones in the innovator product, due to the strong relationship between the manufacturing processes of biopharmaceuticals and the characteristics of the final product. Moreover, since no analytical techniques are currently available for detecting or predicting all biological and clinical properties of proteins, differences between biopharmaceutical products can easily remain undetected [3].

If the copy of a biological medicinal product does not meet the conditions in the definition of generic medicinal products, the requirements for MA applications are based on the demonstration of the similar nature of the two biological products through comparability studies,
Table 1. Dossier for a similar biological medicinal product

$\begin{array}{ll}\text { Module } 1 & \text { Normal requirements } \\ \text { Module 2 } & \text { Normal requirements } \\ \text { Module } 3 & \text { Full + comparability exercise } \\ \text { Module } 4 & \text { Comparability exercise } \\ \text { Module 5 } & \text { Comparability exercise }\end{array}$

named the 'comparability exercise'. The comparability exercise is needed to generate evidences substantiating the similar nature in terms of quality, safety and efficacy of the new similar biological medicinal product and the chosen reference medicinal product authorized in the EC [4].

The number and extent of comparability studies required for granting a MA are detailed in guidelines issued by EMEA's Committee for Medicinal Products for Human Use (CHMP). These guidelines cover a range of issues including manufacturing, demonstration of comparability for quality (Module 3), non-clinical (Module 4) and clinical study (Module 5) reports, physicochemical and biological analyses and clinical trial requirements, and additional data (i.e. toxicological and other non-clinical and appropriate clinical data) whose relevance has to be determined on a case-by-case basis, due to the complexity and diversity of the products. The purpose is to demonstrate the similar nature of the biosimilar and the reference product in terms of quality, safety and efficacy.

\section{Regulatory Policy: EMEA Guidelines}

The comparability exercise has been introduced by the Food and Drug Administration (FDA) to allow manufacturers of 'biopharmaceuticals well-characterized products', i.e. proteins whose identity, purity, impurities, potency and quantity can be determined and controlled, to implement changes in the manufacturing process - such as change in manufacturing site, or modification to cell and seed strains, or fermentation and purification processes - without conducting additional clinical trials to demonstrate efficacy.

Afterwards, in 2000 and 2002, EMEA issued two guidelines on comparability of medicinal products containing biotechnology-derived proteins as active substance after a change in manufacturing process. Subsequently, EMEA broadened their scope to medicines 
Table 2. MA application types for biological medicinal products in the USA

\begin{tabular}{ll}
\hline Active substance class & Application type \\
\hline Heparins & NDA \\
Growth hormones & NDA \\
Insulin & NDA \\
Epoetins & BLA \\
Interferons & BLA \\
G-CSF & BLA \\
Monoclonal antibodies & BLA \\
\hline
\end{tabular}

produced by different manufacturers, publishing the guideline on similar biological medicinal products in 2004 (overarching guideline) and guidelines covering quality issues, non-clinical and clinical issues and immunogenicity assessment of biotechnology-derived therapeutic proteins, all of which can be found on EMEA's website [5].

Additional product-class specific guidelines on preclinical and clinical studies have been developed for a number of therapeutic proteins, such as rHuEPO, providing guidance on appropriate pharmacodynamic and toxicological studies (in the non-clinical section), and on pharmacodynamic, pharmacokinetic, efficacy and safety studies (in the clinical section).

It is clear that the dossier for a biosimilar is much more cumbersome than that of a generic medicinal product, since it comprises at least full Modules 1 and 2, a full Module 3 including the Comparability exercise, and Modules 4 and 5 which consist of the Comparability exercise (table 1).

In March 2006, EMEA published a Guidance on Similar Medicinal Products containing Recombinant Erythropoietins [6] as an Annex to Guideline on Similar Biological Medicinal Products containing BiotechnologyDerived Proteins as Active Substance: Non-Clinical and Clinical Issues.

In 2008, the experience gained with epoetin alpha biosimilar products has prompted the development of a new guideline [7], currently in draft, which revises some critical aspects.

Concerning clinical safety, the use of a validated, highly sensitive antibody assay, able to detect both early and late immune responses, is now mandatory. The development of neutralizing antibodies and pure red cell aplasia (PRCA) are taken into account as a major poten- tial safety concern, since they are unlikely to be captured premarketing, due to their rarity. Moreover, since the SC route is usually more immunogenic than the IV and patients with renal anemia constitute the population at risk for developing anti-epoetin antibody-induced PRCA, the immunogenicity database should include a sufficient number of SC-treated patients with renal anemia, unless SC use in this population is not applied for.

No changes regard the feasibility of extrapolation to other indications of the reference medicinal product as long as it is applied to the same route of administration. Moreover, the clinical efficacy has to be demonstrated with at least two adequately powered, randomized, parallel group clinical trials while in the proposed draft the number of clinical trials is not specified.

In the new guideline, similar efficacy between the test and the reference product should be ensured for both the IV and SC routes of administration, either by performing separate clinical trials for both routes or by performing one clinical trial for one route and providing adequate bridging data for the other route (new possibility). In our opinion, this new possibility is a matter of concern. To the best of our knowledge, not a clear single case of PRCA has been reported using rHuEPO administered only by IV, being all the reported cases of PRCA associated with the SC use of rHuEPO or with the use SC and IV in the same patient. Thus, while it could be possible to translate the safety information related to the risk of PRCA (and possibly of other immunological side effects) from the experience with the SC to the IV route of administration, the other side around, that is to translate the safety information collected in trials using rHuEPO only IV to the SC route of administration, would rise great safety concerns.

\section{FDA's Perspective on Biosimilars}

At present the EMEA guidelines are the only clear regulatory effort concerning biosimilars (called follow-on proteins in the USA) worldwide. However, now that patent rights of many biotechnological originators are likely to expire in the USA, more in-depth regulation about copy drugs will be needed also in this country. To this end, EMEA's regulatory experience represents an important reference for the new policy on biosimilars that the FDA is expected to develop in the near future.

It must be reminded though that there are significant differences in the regulatory frameworks of biological medicines in the USA and Europe. FDA has different 
Table 3. Biosimilars of epoetin alpha which entered the EU market

\begin{tabular}{|c|c|c|c|c|c|c|}
\hline Molecule & Trade name & Company & $\begin{array}{l}\text { Manufacturer } \\
\text { responsible for } \\
\text { batch release }\end{array}$ & $\begin{array}{l}\text { Manufacturer } \\
\text { of active } \\
\text { substance }\end{array}$ & $\begin{array}{l}\text { CHMP } \\
\text { pre- } \\
\text { authorization }\end{array}$ & $\begin{array}{l}\text { EMEA } \\
\text { authorization }\end{array}$ \\
\hline HX575 & Binocrit & Sandoz & Hexal & Rentschler Biotechnologie & June 07 & Aug. 07 \\
\hline HX575 & $\begin{array}{l}\text { Epoetin alfa } \\
\text { Hexal }\end{array}$ & Hexal Biotech Forschung & Hexal & Rentschler Biotechnologie & June 07 & Aug. 07 \\
\hline HX575 & Abseamed & Medice Arzneimittel Pütter & Hexal & Rentschler Biotechnologie & June 07 & Aug. 07 \\
\hline Epoetin zeta & Silapo & Stada/Bioceuticals Arzneimittel & Stada & Stada & Oct. 07 & Dec. 07 \\
\hline Epoetin zeta & Retacrit & Hospira & Stada & Stada & Oct. 07 & Dec. 07 \\
\hline
\end{tabular}

statutory approval mechanisms for drugs, regulated under the Federal Food, Drug and Cosmetic (FDC) Act, and biological products, subject to the Public Health Service (PHS) Act, even though some natural source proteins (e.g. insulin, hyaluronidase, menotropins, and human growth hormones) have been traditionally regulated as drugs. Biological products, which also meet the definition of drugs under the FDC Act, include blood-derived products, vaccines, in vivo diagnostic allergenic products, immunoglobulin products, products containing cells or microorganisms, and most protein products.

Both new drug applications (NDAs) under section 505 of the FDC Act and biologics license applications (BLAs) under section 351 of the PHS Act require submission of complete reports of clinical and preclinical data. Though, while the FDC Act provides an abbreviated approval pathway for generics (ANDA - abbreviated new drug application process, established through the 1984 HatchWaxman Amendments), the PHS has no similar provisions [8] (table 2).

Thus, FDA's viewpoint seems to be that only in the case of relatively simple peptide or protein products (already regulated under the FDC Act), technology has progressed to the point where it is becoming possible to assess the degree of similarity between the innovator and a follow-on product, and an abbreviated pathway can be envisaged (a new authority for the FDA to approve followon biologics has been proposed in FDA's Fiscal Year 2010 Budget [9]). The same does not hold true for biologic products, because of the complexity of manufacturing and characterizing a biologic. Thus, the PHS Act emphasizes the importance of appropriate manufacturing control for products and it has no provision for an abbreviated route $[10,11]$.

\section{Critical Aspects of Medicinal Products Containing rHuEPO}

\section{Safety and Efficacy}

The introduction of similar biological medicinal products into clinical practice presents new challenges, due to the potential impact on patient safety. This is particularly true in the case of rHuEPO, the only glycosylated protein contained in authorized biosimilar products so far. Indeed, a number of PRCA cases have been described in patients receiving SC biosimilar of epoetin alpha manufactured outside the EC $[12,13]$.

Five products containing rHuEPO, biosimilar of the reference product Eprex/Erypo ${ }^{\circledR}$ (epoetin alpha, Janssen-Cilag $\mathrm{GmbH}$ ), have been approved by the EMEA (table 3):

- Abseamed ${ }^{\circledR}$, Binocrit ${ }^{\circledR}$ and Epoetin alfa Hexal ${ }^{\circledR}$ are epoetin alpha products, all of them produced by Rentschler Biotechnologie, GmbH (HX575), but marketed by three different companies. Comparability exercises demonstrated that the isolated active substance 'is representative of the active substance present in the reference medicinal product' and the analysis of the protein part did not reveal any significant difference with the reference product. Differences were observed at the glycosylation level: phosphorylated high mannose type structures in the biosimilar products were detected at higher levels than in Eprex/Erypo. However, they are considered to be common glycoforms of recombinant erythropoietins and their presence is described in the literature for other recombinant cytokines and a large variety of non-lysosomal proteins from human plasma and they do not impact on efficacy or safety. In addition, neuraminic acid differences were observed. However, biosimilar drug substance showed lower values of $\mathrm{N}$-glycolyl-neuraminic acid 
and diacetylated neuraminic acids as compared to Eprex/Erypo [14].

- Retacrit ${ }^{\circledR}$ and Silapo ${ }^{\circledR}$ manufactured by Norbitec $\mathrm{GmbH}$ have been assigned the international non-proprietary name (INN) epoetin zeta, rather than epoetin alpha. It was demonstrated that 'the isolated active substance used in the comparability exercise is representative of the active substance present in the reference medicinal product' and, the data obtained on the protein backbone demonstrated equivalence between the two products. With respect to the glycan moieties, 'the overall range of structures was found to be comparable. However, the amount of glycoforms without an O-glycan chain was slightly higher for epoetin zeta as compared to epoetin alpha. On the other hand, the amounts of undesired variants of sialic acid, N-glycolyl neuraminic acid and O-acetyl neuraminic acid were higher in the reference product as compared to epoetin zeta' [15]. It has also been reported that the protein content of Eprex ${ }^{\circledR}$ is higher than that of Retacrit [16]. The clinical implications of these small molecular differences are still unknown.

\section{Naming}

The approach used so far by the WHO for EPO-based products, consists of: (1) identification of the group with the stem -poetin, (2) indication of differences in the amino acid chain by using a random prefix, and (3) indication of differences in the glycosylation pattern by a Greek letter added as second word to the name (e.g. epoetin alpha).

According to this scheme, 10 INNs have been assigned to $\mathrm{rHuEPO}$ and its derivates to date: darbepoetin alpha, epoetin alpha, epoetin beta, epoetin gamma, epoetin delta, epoetin epsilon, epoetin zeta, epoetin theta, epoetin kappa, epoetin omega [17].

It is important to emphasize that the choice of INNs of biotechnology medicines is closely linked to the issue of substitution and interchangeability.

\section{Substitution and Interchangeability}

Interchangeability follows from therapeutic equivalence and is related to intrinsic drug characteristics. In contrast, a substitution program can be introduced by the Public Administration on the basis of interchangeability and is related to administrative procedures than can be implemented differently in different Member States. The term 'substitution' here means 'automatic substitution' at the dispensing level, without prejudice to the freedom the physicians has to change a prescription on the basis of his knowledge and clinical data.

Biosimilars and Regulatory Authorities
The originator drug and its biosimilar products (or biosimilar products from different manufacturers) are not interchangeable as bioequivalence cannot be used to demonstrate therapeutical equivalence, and the active substance is similar but not identical between the two products. Thus, automatic substitution at the dispensing level, without the physician's knowledge or explicit prior consent, should not be permitted, since, apart from clinical concerns, it may lead to difficulties in monitoring safety profiles of products compromising pharmacovigilance programs. Moreover, frequent changes in administered molecules may increase immunogenicity of these drugs. However, in the area of substitution, the European Union (EU) leaves a broad margin of discretion, giving each Member State the faculty to set substitution policies, which follows very strict rules in most cases (e.g. in France, Spain, Italy).

In many Member States, if the prescription specifies only the INN, the pharmacy may dispense any product with that INN or indeed any of a group of products deemed therapeutically equivalent or generically substitutable. Since this approach is clearly inadequate for biological medicinal products, the need emerges to reduce patient safety risks associated with switching from one product to another without the treating physician's knowledge and permission. The safety and efficacy of biological medicinal products are highly dependent on a variety of factors, including the product's manufacturing processes and formulation. Although this is particularly true with glycosylated proteins, there are concerns with all recombinant protein drug substances $[18,19]$.

\section{Cost}

One of the main benefits of biosimilars should be a reduced cost compared with their respective innovator products. Nevertheless, savings cannot be expected to be in the same order of magnitude as in the case of generics, due to high manufacturing costs, the need to perform reduced non-clinical and clinical studies, and an appropriate pharmacovigilance program. As an example, in the UK the list prices of four biosimilars (Omnitrope ${ }^{\circledR}$, Binocrit, Retacrit, and Ratiograstim ${ }^{\circledR}$ ) compared with their respective innovator products are about $10-25 \%$ less [20].

\section{Conclusions}

Biological medicinal products are very complex molecules and present a specific public health and safety challenge that is not ordinarily presented by synthetic

Nephron Clin Pract 2011;117:c1-c7 
medicines. Guaranteeing consistency in the production of these agents has already proved difficult. Incidences such as the increased occurrence of PRCA cases in 1998 demonstrated how one small subtle change in the manufacturing process can alter the product's characteristics. In light of this upsurge in cases of PRCA, which has been linked to several possible causes including a small, deliberate change in the formulation of one brand of erythropoietin-stimulating agent, there is increased concern about the potential of slight molecular differences to have significant immunogenic consequences [21].

Thus, it is important to be aware that biotechnological medicinal products, including biosimilars, may be unfortunately associated with rare adverse events, or medically significant increases in such events, that cannot be detected through any reasonable course of pre- market testing. It is therefore essential that adverse events with biological products be attributable to the correct product and that inappropriate substitution is avoided. We would like to underline that this is true not only for all the biosimilars but also for all the originators and that substitution of a biosimilar for either an originator or another biosimilar should be approached with great caution.

\section{Conflict of Interest Declaration}

Francesco Locatelli is a member of an advisory board of Affymax, Amgen-Dompè, Jansen Cilag, Merck, Roche and of a Safety Board of Sandoz. Paola Minghetti, Paolo Rocco and Lucia Del Vecchio declare that they have no conflicts of interest.

\section{References}

1 Regulation (EC) No. 726/2004 of the European Parliament and of the Council of 31 March 2004 laying down Community procedures for the authorisation and supervision of medicinal products for human and veterinary use and establishing a European Medicines Agency, as amended.

2 Directive 2001/83/EC of the European Parliament and of the Council of 6 November 2001 on the Community code relating to $\mathrm{Me}$ dicinal Products for Human Use, as amended.

3 Schellekens H: Biosimilar therapeutics what do we need to consider? Nephrol Dial Transplant Plus 2009;2(suppl 1):i27-i36.

4 Guideline on Similar Biological Medicinal Product (CHMP/437/04).

5 http://www.emea.europa.eu/htms/human/ humanguidelines/multidiscipline.htm.

6 Annex to Guideline on Similar Biological Medicinal Products Containing Biotechnology-Derived Proteins as Active Substance: Non-Clinical and Clinical Issues - Guidance on Similar Medicinal Products Containing Recombinant Erythropoietins (CHMP/ 94526/05), March 2006.

7 Guideline on similar medicinal products containing recombinant erythropoietins (EMEA/CHMP/BMWP/301636/08), currently in draft.

8 The Law of Biologic Medicine. Statement of Lester M. Crawford, DVM, PhD, Acting Commissioner of Food and Drugs, Department of Health and Human Services before the Senate Committee on the Judiciary, June 23, 2004 (available at: http://www.fda.gov/ NewsEvents/Testimony/ucm113745.htm).
9 Summary of the FDA's FY 2010 Budget (available at: http://www.fda.gov/AboutFDA/ReportsManualsForms/Reports/BudgetReports/ucm153154.htm).

10 'Frequently Asked Questions about Therapeutic Biological Products' (available at: http://www.fda.gov/Drugs/Development ApprovalProcess/HowDrugsareDevelopedand Approved/ApprovalApplications/TherapeuticBiologicApplications/ucm 113522. htm).

11 Demonstration of Comparability of Human Biological Products, Including Therapeutic Biotechnology-Derived Products. Center for Biologics Evaluation and Research (CBER), Center for Drug Evaluation and Research (CDER) April 1996 (available at: http://www. fda.gov/Drugs/GuidanceComplianceRegulatoryInformation/Guidances/ucm122879. htm).

12 Keithi-Reddy SR, Kandasamy S, Singh AK: Pure red cell aplasia due to follow-on epoetin. Kidney Int 2008;74:1617-1622.

13 Praditpornsilpa K, Tungsanga K, Eiam-Ong S: The Immunogenicity of Biosimilar Recombinant Human Erythropoietin by Subcutaneous Injection for the Treatment of Anemia in Chronic Kidney Disease. Abstract TH-PO130. Renal Week, San Diego/ CA, 2009.

14 Scientific Discussion: Epoetin alpha Hexal EPAR, Procedure No. EMEA/H/C/726, Revision 7, published 13/10/09 (available at: http://www.emea.europa.eu/humandocs/ Humans/EPAR/epoetinalfahexal/epoetinalfahexal.htm).
15 Scientific Discussion, Retacrit EPAR, Procedure No. EMEA/H/C/726, Revision 4, published 06/02/09 (available at: http://www. emea.europa.eu/humandocs/Humans/ EPAR/retacrit/retacrit.htm).

16 Schellekens H: Assessing the bioequivalence of biosimilars. The Retacrit case. Drug Discov Today 2009; 14:495-499.

17 International Nonproprietary Names (INN) for biological and biotechnological substances (a review). World Health Organization, Programme on International Nonproprietary Names (INN), INN Working Document 05.179, 2007 (available at: http:// www.who.int/medicines/services/inn/publication/en/index.html).

18 European Biopharmaceutical Enterprises (EBE), EBE-EFPIA position paper - Naming of biosimilar medicinal products: options for addressing unique safety concerns (2006) (available at: www.ebe-biopharma.org).

19 European Biopharmaceutical Enterprises (EBE), EBE-EFPIA position paper: Inapplicability of automatic substitution rules to biotechnology products, including biosimilar products (2006) (available at: www.ebebiopharma.org).

20 Hughes DA: Biosimilars: Evidential Standards for Health Technology Assessment. Clin Pharmacol Ther 2010;87:257-261.

21 Locatelli F, Goldsmith D: Biosimilars: uncharted territory. J Nephrol 2007;20:265267. 


\section{Editorial Comment}

M. El Nahas, Sheffield

In this review, Minghetti and her colleagues detail the importance of steps taken by the EU to licence biosimilars. Biosimilars aim to mimic original biopharmaceutical products. But in fact, they differ from the bio-innovator drugs they mimic in many aspects often including size, molecular configuration and complexity of the active substance as well as the nature of the manufacturing process. Minor changes in manufacturing can have serious implications in terms of safety and efficacy of the product [1]. It is therefore essential that meticulous regulatory scrutiny is applied to the marketing of biosimilars or follow-on proteins as they are called in the USA. This review highlights steps taken by the European Medicines Agency (EMEA) and the US Food and Drug Administration (FDA) to minimize risk of marketing unsafe biosimilars [2].

\section{References}

Misra A: Are biosimilars really generics? Expert Opin Biol Ther 2010; 10:489-494.

2 Hennessy S, Leonard CE, Platt R: Assessing the safety and comparative effectiveness of follow-on biologics (biosimilars) in the United States. Clin Pharmacol Ther 2010;87:157-159. 